\title{
Electrochemical Sensor for Ethylene Glycol using Reduced Graphene Oxide/AuNp/Ni(OH), Modified Glassy Carbon Electrode
}

\author{
Victor Magno Paiva ${ }^{\text {(1), Kelly Leite dos Santos Castro Assis }}{ }^{b}$ (), José G. A. Rodrigues ${ }^{a}$, \\ Carlos Alberto Senna ${ }^{b}$, Paula F. de Aguiar ${ }^{a}$, Bráulio Soares Archanjo ${ }^{b}$,Emerson Schwingel Ribeiro ${ }^{a}$, \\ Carlos Alberto Achete ${ }^{b}$ Eliane D'Elia ${ }^{a}$ (1) \\ ${ }^{a}$ Universidade Federal do Rio de Janeiro, Instituto de Química, Cidade Universitária, 21941-909, Rio \\ de Janeiro, Brasil. \\ ${ }^{b}$ Instituto Nacional de Metrologia, Qualidade e Tecnologia, 25250-020, Duque de Caxias, Brasil.
}

Received: December 08, 2020; Revised: June 25, 2021; Accepted: June 30, 2021

\begin{abstract}
An electrochemical sensor based on a modified glassy carbon electrode (GCE) with reduced graphene oxide and $\mathrm{Ni}-\mathrm{Au}$ nanoparticles $\left(\mathrm{Ni}(\mathrm{OH})_{2} / \mathrm{AuNp} / \mathrm{rGO} / \mathrm{GCE}\right)$ was developed for the determination of ethylene glycol. The graphene oxide was reduced electrochemically at the electrode surface by chronoamperometry, the gold nanoparticles were deposited by chronopotentiometry while the nickel hydroxide nanoparticles were deposited by cyclic voltammetry. The characterization of graphene oxide was performed by Raman spectroscopy, X-ray diffraction (XRD) and transmission-mode scanning electron microscopy (TSEM), while the modified electrodes were characterized by scanning electron microscopy (SEM) and electron dispersive spectroscopy (EDS) analysis. The determination of ethylene glycol was performed by cyclic voltammetry due to the regeneration of the active sites, preventing loss of the sensor signal. The modified GCE with $\mathrm{rGO}$ and $\mathrm{Ni}(\mathrm{OH})_{2} / \mathrm{AuNp}$ showed a good performance obtaining a linear range of 0.24 to $1.4 \mathrm{mmol} \mathrm{L}^{-1}$ with a correlation coefficient of 0.9903 , limits of detection and quantification (49 and $162 \mu \mathrm{mol} \mathrm{L}^{-1}$, respectively) and high stability with 500 continuous analysis cycles.
\end{abstract}

Keywords: Ethylene glycol, nickel nanoparticles, gold nanoparticles, reduced graphene oxide, cyclic voltammetry.

\section{Introduction}

Ethylene Glycol (EG) is an alcohol widely used in industry due to its physical and chemical characteristics such as high flash point, low freezing point, low volatility, low flammability, thermodynamically stable and high availability ${ }^{1}$. In the plastic industry, the EG is a precursor of the polyethylene terephthalate very used to produce PET bottles, in the automobile industry it is the main component of the cooling fluid in combustion engines ${ }^{2-4}$, in the petroleum industry it is used as a hydrate formation inhibitor ${ }^{5-7}$, in other sectors as solvent ${ }^{8}$ and as antifreeze on airport and highway runways².

However, the use of this reagent can cause serious problems not only to the environment, but also to human health as well as problems in the lubrication of machines. When there is a leakage of the refrigerant oil in the car engine, it causes a decrease in the tribological properties of the lubricating oil, which can lead to the melting of the cylinders and even the fusion of the engines ${ }^{4,9,10}$. In the oil industry, a large quantity of this reagent is used, for this reason, is necessary to recover the environmental impact and control the quality of the fuel produced ${ }^{11,12}$. Finally, in contact with the environmental, the alcohol is easily absorbed

*e-mail: eliane@iq.ufrj.br (by the rivers, soil and groundwater) and consequently the contamination of living beings with the ethylene glycol is facilitated. Ethylene glycol when metabolized generates extremely harmful metabolites to the body, causing renal failure and damage to the nervous system, which makes it important to control the concentration of $\mathrm{EG}^{13-15}$.

Classical techniques such as gas chromatography, liquid chromatography, mass spectroscopy or even the combination of them have been widely used for the control and analysis of EG in samples, however their use can often become impracticable. Even with these techniques it is possible to analyze and detect small amounts of alcohol (using the LC-MS/MS technique, a detection limit of $0.564 \mathrm{mmol} \mathrm{L}^{-1}$ was obtained), these are expensive, laborious and time-consuming techniques, which makes it interesting to develop alternative methods $^{8,9,16-18}$.

Electrochemical methods have been widely used for quantification or identification of analytes in several matrices due to their relative low cost, high sensitivity, high selectivity, easy miniaturization, convenience, rapid analysis and lower consumption of reagents and solvents, which are principles of green chemistry ${ }^{19-22}$. Thus, the search for electrocatalytic materials has been studied for $\mathrm{EG}$ analysis and its quantification or its use for energy conversion. Nickel has been studied 
for alcohol oxidation, in general, because it has low cost compared to noble metals, good stability in alkaline medium and wide operating range ${ }^{23}$. In alkaline medium, there is the formation of redox pairs of nickel hydroxide/oxyhydroxide (in the forms $\alpha-\mathrm{Ni}(\mathrm{OH})_{2}, \beta-\mathrm{Ni}(\mathrm{OH})_{2}$ and $\left.\gamma-\mathrm{NiOOH}\right)$, being the $\alpha-\mathrm{Ni}(\mathrm{OH})_{2}$, and $\gamma-\mathrm{NiOOH}$ the redox pair which presents the higher catalytic activity for alcohol oxidation ${ }^{24-26}$.

The combination of electrocatalytic materials with the reduced graphene oxide ( $\mathrm{rGO}$ ) has presented great advantages in the analytical area, the synergism between the materials and the combination of their properties increase the sensor response, having gain in sensor sensitivity ${ }^{27,28}$. The rGO use increases the surface area providing dense active sites, electrical conductivity, durability and mechanical stability ${ }^{29,30}$. The combination of gold with nickel in electrochemical sensors, as already reported in studies, yields excellent results regarding the electrocatalytic activity, durability, poisoning resistance and increased charge transfer ${ }^{28,31-33}$.

The rGO can be obtained by thermal, photocatalytic, chemical reduction, electrochemical processes or by microwaveassisted techniques ${ }^{34,35}$. Electrochemical reduction has been widely used because in addition to being considered a green approach (the most used reducing agents are hydrazine, ethylenediamine, $\mathrm{NaBH}_{4}$ and urea, toxic reagents that cause serious risks to the environment and people) it produces graphene films directly on the substrate, does not require chemical reducers, is easy to prepare and has a smaller number of functional groups with oxygen than other reduction techniques, thus increasing its conductivity ${ }^{34-37}$.

The objective of this study is to develop a sensor for ethylene glycol analysis, based on the modification of the GCE surface with rGO and nanoparticles of nickel and gold $\left(\mathrm{Ni}(\mathrm{OH})_{2} / \mathrm{AuNp} / \mathrm{rGO} / \mathrm{GCE}\right)$. The sensor was evaluated considering their analytical performance where figures of merit as detection limits, sensitivity and linearity.

\section{Experimental}

\subsection{Reagents and materials}

Ethylene glycol ( $\geq 99.5 \% \mathrm{v} / \mathrm{v})$ and potassium hydroxide ( $\geq 85 \% \mathrm{w} / \mathrm{w}$ ) were purchased from Isofar (Rio de Janeiro, RJ, Brazil). Chloroauric acid ( $\geq 99.5 \% \mathrm{v} / \mathrm{v})$, sulfuric acid $(95.0-98.0 \% \mathrm{v} / \mathrm{v})$, sodium chloride $(\geq 99.0 \% \mathrm{w} / \mathrm{w})$, sodium hydrogen phosphate $(\geq 99.0 \% \mathrm{w} / \mathrm{w})$ and potassium hydrogen phosphate $(\geq 99.0 \% \mathrm{w} / \mathrm{w})$ were bought from Sigma-Aldrich (Rio de Janeiro, RJ, Brazil). Expanded Graphite was obtained from Nacional de Grafite (São Paulo, SP, Brazil). All solutions were prepared with ultra-pure water $(18.2 \mathrm{M} \Omega \mathrm{cm})$ from a purification system MILLI-Q ${ }^{\circledR}$ (Massachusetts, USA). All reagents were used without prior purification.

\subsection{Electrochemical apparatus}

Electrochemical analyzes were performed using the Autolab PGSTAT204 potentiostat/galvanostat (Metrohm AUTOLAB, Netherlands). Data processing was performed with NOVA 2.0. As a working electrode, it was used a glassy carbon electrode $\left(\right.$ area $=3.14 \mathrm{~mm}^{2}$ ) obtained from Lab Solutions (São Paulo, SP, Brazil), which was modified with reduced graphene oxide, nickel and gold nanoparticles $\left(\mathrm{Ni}(\mathrm{OH})_{2} /\right.$
$\mathrm{AuNp} / \mathrm{rGO} / \mathrm{GCE}$ ). Platinum wire and $\mathrm{Ag}|\mathrm{AgCl}| \mathrm{KCl}_{\text {(sat.) }}$ ( $3 \mathrm{~mol} \mathrm{~L}^{-1}$ ) were used as auxiliary electrodes and reference electrodes, respectively, in a $15 \mathrm{~mL}$ electrochemical cell.

\subsection{Synthesis of the reduced graphene oxide}

\subsubsection{Graphite oxide preparation}

The graphite oxide was prepared by modified Hummers' method using expanded graphite according to the previous work $^{38}$. The general procedure is as follows: concentrated $\mathrm{H}_{2} \mathrm{SO}_{4}(9.2 \mathrm{~mL})$ was added to a mixture of expanded graphite $(0.4 \mathrm{~g})$ and $\mathrm{NaNO}_{3}(0.2 \mathrm{~g})$ in an ice bath. After that, $\mathrm{KMnO}_{4}(1.2 \mathrm{~g})$ was added slowly to keep the temperature of reaction lower than $20^{\circ} \mathrm{C}$. The mixture was warmed to $35^{\circ} \mathrm{C}$ and stirred for $30 \mathrm{~min}$. After this, water $(18.2 \mathrm{~mL})$ was added slowly to the medium promoting a large exothermic reaction and increasing the temperature up to $98{ }^{\circ} \mathrm{C}$. An external heating was used to maintain the reaction temperature at $98{ }^{\circ} \mathrm{C}$ for $15 \mathrm{~min}$, then a water bath was used to cool the reaction for $10 \mathrm{~min}$. Additional water $(55.3 \mathrm{~mL})$ and $30 \%$ $\mathrm{v} / \mathrm{v} \mathrm{H}_{2} \mathrm{O}_{2}(0.4 \mathrm{~mL})$ were added to stop reaction, producing another exothermic process.

\subsubsection{Exfoliation of graphite oxide}

To obtain graphene oxide, a graphite oxide solution with a concentration of $1 \mathrm{mg} \mathrm{mL}^{-1}$ was prepared and exfoliated by ultrasound for 20 hours. According to our previous work, small size GO sheet was obtained using a conventional $70 \mathrm{~W}$ ultrasonic bath and $20 \mathrm{~h}$ of exfoliation ${ }^{39}$.

\subsubsection{Characterization of graphite oxide}

Raman spectroscopy analyses were carried out on a Renishaw inVia spectrometer (Renishaw, Wotton-under-Edge, England) with a $514.5 \mathrm{~nm}$ laser line at a power of $0.1 \mathrm{~mW}$ and $100 x$ objective lens. All Raman spectra were obtained from accumulation and averaging of 10 scans with accumulation time of 10 seconds/scan and the reported spectra represent the average of twenty five measurements made at different points of the sample.

X-ray diffraction analysis were performed on a D8 Focus diffractometer (Bruker-AXS, Karlsruhe, Germany) with Ni-filtered $\mathrm{Cu} \mathrm{K} \alpha$ characteristic radiation with a $2 \theta$ step of 0.02 and a collection time of $20 \mathrm{~s}$ per step. A thin film of graphite oxide was prepared by dripping the sample suspension onto a Si wafer and subsequently drying it in air.

\subsection{Modification of glassy carbon electrode with reduced graphene oxide and nanoparticles of nickel and gold}

For the $\mathrm{Ni}(\mathrm{OH})_{2} / \mathrm{AuNp} / \mathrm{rGO} / \mathrm{GCE}$ fabrication, $5 \mu \mathrm{L}$ of graphene oxide suspension were applied on the surface of the GCE, after drying in an oven at $35^{\circ} \mathrm{C}$ the electrode was subjected to a chronoamperometry technique at $-1.5 \mathrm{~V}$ for $60 \mathrm{~s}$ in phosphate buffer $\mathrm{pH} 7.4$ for the reduction of graphene oxide.

Then the $\mathrm{rGO} / \mathrm{GCE}$ was subjected to chronopotentiometry at $-0.18 \mathrm{~mA}$ for $350 \mathrm{~s}$ using a $1 \mathrm{mmol} \mathrm{L}^{-1}$ solution of chloroauric acid in $0.05 \mathrm{~mol} \mathrm{~L}^{-1}$ sulfuric acid followed by electrodeposition of nickel hydroxide nanoparticles by cyclic voltammetry technique under the conditions: 300 cycles, $9 \mathrm{~V}$ 
$\mathrm{s}^{-1}$ in the range of potential -1.4 to $-0.5 \mathrm{~V}$ using a solution of $3 \mathrm{mmol} \mathrm{L}^{-1}$ of nickel nitrate in $1 \mathrm{~mol} \mathrm{~L}^{-1}$ ammonium chloride. For the stabilization of $\alpha-\mathrm{Ni}(\mathrm{OH})_{2}$ the electrode was subjected to chronoamperometry at $-0.16 \mathrm{~V}$ for $30 \mathrm{~s}$ in a solution containing $10 \mathrm{mmol} \mathrm{L}^{-1} \mathrm{Cd}^{+2}, \mathrm{Co}^{+2}$ and $\mathrm{Ni}^{+2}$ at 0.3:2.7:7.0 (stoichiometric) in a $20 \mathrm{mmol} \mathrm{L}^{-1}$ potassium nitrate solution ${ }^{25,40,41}$. Finally, the electrode was submitted to cyclic voltammetry technique in $0.50 \mathrm{~mol} \mathrm{~L}^{-1} \mathrm{KOH}$ under the following conditions: 20 cycles, $0.05 \mathrm{~V} \mathrm{~s}^{-1}$ in the range -0.3 to $0.7 \mathrm{~V}$ to activate the electrode.

All the experimental conditions described above in modifying the $\mathrm{GCE} / \mathrm{rGO}$ with $\mathrm{Au}$ and $\mathrm{Ni}(\mathrm{OH})_{2}$ nanoparticles were previously optimized from the screening study using a Plackett-Burman design (PB) (Table S1). With the responses obtained in the PB design (Table S2) the effects of the parameters were estimated (Table S3), where from these results the active parameters were applied to the central composite design (Table S4) generating the model's response surface (Figure S1), as can be seen in the Supplementary Material.

\subsection{Electrochemical study of modified electrodes}

To understand what the modifications are providing for the electrode, the heterogeneous electron transfer (HET) rate constant $\left(\mathrm{k}^{0}\right)$, electroactive area and the EG signal for each modification were studied. For the study of $\mathrm{k}^{0}$ each electrode was subjected to cyclic voltammetry technique in $20 \mathrm{mmol} \mathrm{L}^{-1}\left[\mathrm{Fe}(\mathrm{CN})_{6}\right]^{3-}$ in $\mathrm{KCl} 3 \mathrm{~mol} \mathrm{~L}^{-1}$ where through the potential difference of the oxidation and reduction peaks it was calculated the $\mathrm{k}^{0}$ according to the Nicholson equation $^{42-44}$ (Equation 2)

$\Psi=\frac{\gamma^{\alpha} k^{0}}{\sqrt{\Pi \alpha D_{0}}}$

Where $\gamma=\left(\frac{D_{o}}{D_{r}}\right)$ and $\alpha=\frac{F v}{R T}, D_{0}$ and $D_{r}\left(\mathrm{~cm}^{2} \mathrm{~s}^{-1}\right)$ are the corresponding oxidation/reduction diffusion coefficients, as it is a system in equilibrium $\frac{D_{0}}{D_{r}} \cong 1$, then

$\Psi \sqrt{\frac{\Pi D_{o} n F v}{R T}}=k^{0}$

Where $\mathrm{k}^{0}$ is the electrochemical heterogeneous rate constant, $\alpha$ is the transfer coefficient, $\mathrm{n}$ is the number of electrons transferred, $\mathrm{v}$ is the scan rate $\left(\mathrm{V} \mathrm{s}^{-1}\right), \mathrm{R}$ is the gas constant, $\mathrm{F}$ is the Faraday constant, $\mathrm{T}(\mathrm{K})$ is the temperature of the system, and $\Psi$ is a dimensionless charge transfer parameter that can be calculated by the equation below ${ }^{44}$ :

$\Psi=\frac{-0.6288+0.0021 X}{1-0.017 X}$

Where $\mathrm{X}$ corresponds to $\Delta \mathrm{E}_{\mathrm{p}}$ at different scan rates.

The electroactive area was calculated according to the Randles-Sevcik ${ }^{45-47}$ (Equation 4) equation. The electrode was subjected to cyclic voltammetry technique in $20 \mathrm{mmol} \mathrm{L}^{-1}\left[\mathrm{Fe}(\mathrm{CN})_{6}\right]^{3-}$ in $\mathrm{KCl} 3 \mathrm{~mol} \mathrm{~L}^{-1}$
$I p=2.69 \times 10^{5} n^{\frac{3}{2}} A C D^{\frac{1}{2}} v^{\frac{1}{2}}$

Where I is the peak current (A), A is the electroactive area of the electrode $\left(\mathrm{cm}^{2}\right), \mathrm{n}$ is the number of electrons, $\mathrm{C}$ is the concentration $\left(\mathrm{mol} \mathrm{cm} \mathrm{cm}^{-3}\right), \mathrm{D}$ is the diffusion coefficient $\left(6.2 \times 10^{-6} \mathrm{~cm}^{2} \mathrm{~s}^{-1}\right)^{48}$ and $v\left(\mathrm{~V} \mathrm{~s}^{-1}\right)$ is the rate scan.

The EIS technique was performed for the electrodes, at $0.4 \mathrm{~V}$, with a disturbance amplitude of $10 \mathrm{mV}$, using a frequency range from $200 \mathrm{kHz}$ to $0.01 \mathrm{~Hz}$ with 7 points per decade. This technique is used to verify the resistive and capacitive characteristics of the electrodes, comparing the efficiency of the electrodes under study.

\subsection{Characterization of electrodes surface}

The evaluation of morphological characteristics such as distribution, form and size of particles on the surface of the electrodes, were studied by scanning electron microscopy with X-ray energy dispersive spectroscopy for elemental analysis. SEM and EDS were performed in a FEI Helios Nanolab 650 working at 10 or $20 \mathrm{kV}$. These analyses were performed using carbon screen printed electrodes (SPE).

\subsection{Partial validation}

The method was submitted to an analytical validation to evaluate not only the reliability of the results obtained, but also to know if it was adequate for EG analysis. In this study some analytical figures of merit such as linearity, limit of detection (LOD), limit of quantification (LOQ), selectivity, precision (repeatability and intermediate precision) and recovery were evaluated, as suggested by international and Brazilian guidelines ${ }^{49,50}$.

\subsubsection{Linearity}

An analytical curve was prepared, in triplicate, with standard solution of ethylene glycol at 6 different concentrations $(0.24$, $0.48,0.72,0.95,1.20$ and $\left.1.43 \mathrm{mmol} \mathrm{L}^{-1}\right)$. For the analysis, a $1.8 \mathrm{~mol} \mathrm{~L}^{-1}$ EG solution in $0.1 \mathrm{~mol} \mathrm{~L}^{-1} \mathrm{KOH}$ was made and aliquots were successively collected using a Hamilton microliter syringe and added to the electrochemical cell containing $0.50 \mathrm{~mol} \mathrm{~L}^{-1} \mathrm{KOH}$. The EG oxidation peak area was evaluated as electrochemical response in function of the analyte concentration.

To evaluate the data homoscedasticity and normality of the residues were used the Cochran ${ }^{51}$ and AndersonDarling $^{52}$ test, respectively, where the $\mathrm{p}$-value was evaluated at a $5 \%$ significance level to assess the hypothesis of variance equality and normality of residuals. Finally, the correlation coefficient between voltammetric peak area and ethylene glycol concentration was obtained with linear regression and evaluated by Pearson's correlation coefficient using $r>0.9900$ as the criterion ${ }^{53}$.

\subsubsection{Limit of detection and limit of quantification}

The limit of detection of the method was obtained from the experimental data of the analytical curve according to Equation 5.

$\mathrm{LOD}=\frac{3 s}{b}$

Where: $s$ is standard deviation of the analytical curve intercept and $b$ is slope of the analytical curve. 
The limit of quantification was estimated as 3.3 times the limit of detection ${ }^{54-56}$.

\subsubsection{Recovery and precision}

The recovery and precision of three different concentration levels (low, medium and high) of the analytical curve were verified. The recovery was evaluated by comparing the average of the triplicates with the theoretical value. The result of repeatability was expressed as the coefficient of variation, also known as the relative standard deviation $(\operatorname{RSD} \%)^{57,58}$.

\subsection{Stability}

In tests of the electrode stability, the sensor was submitted to the cyclic voltammetry technique from -0.3 to $0.7 \mathrm{~V}$ with $0.05 \mathrm{~V} \mathrm{~s}^{-1}$ in $0.50 \mathrm{~mol} \mathrm{~L}^{-1} \mathrm{KOH}$ containing $1.8 \mathrm{~mol} \mathrm{~L}^{-1} \mathrm{EG}$. During the whole study, the voltammetric peak area was used as the analytical response, the first peak area was compared with the last.

\section{Results and Discussion}

\subsection{Characterization of graphite oxide}

Typical Raman spectrum of graphite oxide sample is presented in Figure 1a. The broad $\mathrm{G}$ band at $1580 \mathrm{~cm}^{-1}$ originates from the vibration mode of stretching carbon atoms in the plane with $\mathrm{sp}^{2}$ hybridization, common in graphitic structures ${ }^{59}$. The $\mathrm{D}$ band centered at $1350 \mathrm{~cm}^{-1}$ is A1g symmetry mode produced by out of plane vibrations of carbon atoms, and it becomes active due to the presence of structural defects such as vacancies, edge formation, functional groups containing oxygen and adsorption of molecules on the surface ${ }^{60}$. The ID / IG ratio for graphite oxide was 0.86 showing that the material obtained has a large number of defects.

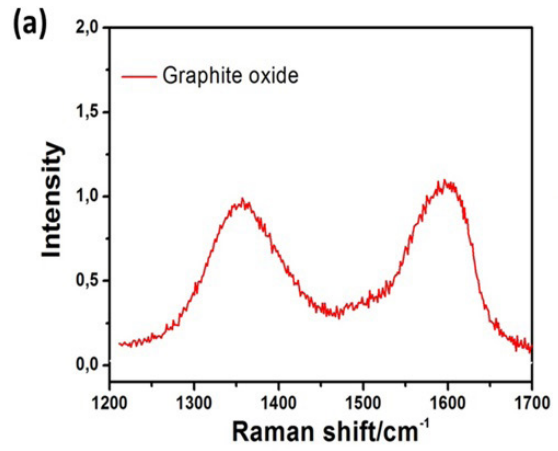

(c)

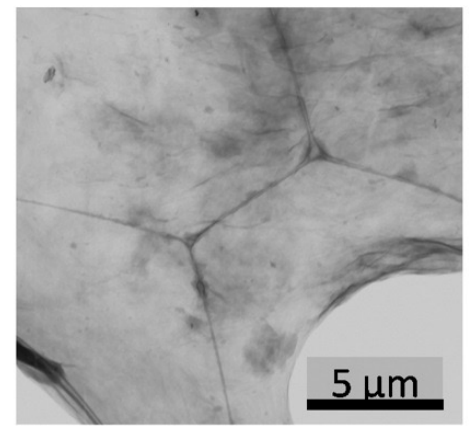

Figure 1. Graphite oxide structural and morphological characterization. Raman (a), XRD patten (b), TSEM image (c) and picture of the freeze-dried graphite oxide (d).
XRD measurements of graphite oxide sample are shown in Figure $1 b$. The material exhibits a characteristic XRD peak at $2 \theta \approx 11^{\circ}$ representing a periodic stacking of graphite oxide sheets ${ }^{61,62}$.

Figure 1c shows a TSEM micrograph of graphite oxide deposited on a lacey carbon TEM grid. This micrograph confirms the membrane-like architecture, reproducing graphite oxide morphology of similar studies ${ }^{61,63}$. Figure 1d shows the picture of freeze-dried graphite oxide.

\subsection{Characterizaiton of reduced graphene oxide modified glassy carbon electrode}

The benefits of using reduced graphene oxide in electrochemical sensors are already well-known and established in the scientific world $^{64,65}$. In Figure 2 it is possible to observe the electrochemical behavior of unmodified (curve A) and modified with reduced graphene oxide (curve B) GCE in $3 \mathrm{~mol} \mathrm{~L}^{-1} \mathrm{KCl}$ solution containing $20 \mathrm{mmol} \mathrm{L}^{-1}$ potassium ferri-ferrocyanide.

The electrochemically active area of the $\mathrm{rGO} / \mathrm{GCE}$ electrode $\left(7.35 \times 10^{-2} \mathrm{~cm}^{2}\right)$ was 1.6 times greater than the value of the unmodified GCE $\left(4.63 \times 10^{-2} \mathrm{~cm}^{2}\right)$. This increase in the $\mathrm{rGO} / \mathrm{GCE}$ area is due to the surface area increase by modification with reduced graphene oxide ${ }^{66}$. The increase in the electrode area increases both the faradaic $\left(i_{p, a}\right.$ and $\left.i_{p, c}\right)$ and capacitive currents as observed in red curve of the Figure ${ }^{65}$. The voltammetric profile of each modification of the electrode is shown in Figure S2.

\subsection{Surface analysis by Scanning Electron Microscopy}

The SEM images of the samples (SPE, $\mathrm{rGO} / \mathrm{SPE}$ and $\left.\mathrm{Ni}(\mathrm{OH})_{2} / \mathrm{AuNp} / \mathrm{rGO} / \mathrm{SPE}\right)$ are shown in Figure 3 at different magnifications.

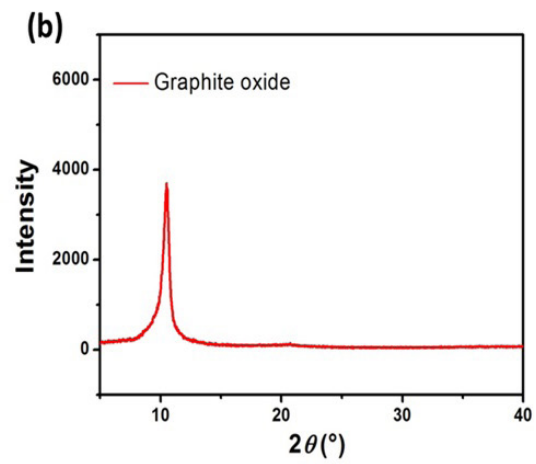

(d)

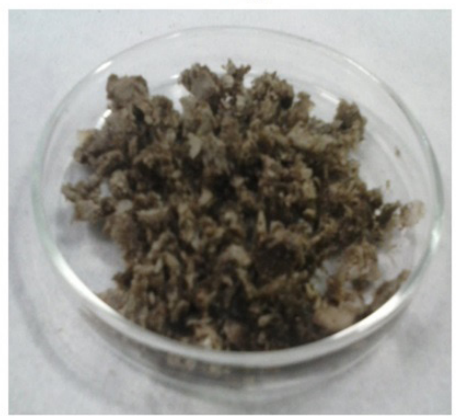


Before modification, the carbon SPE presents a flat surface with some defects (Figure 3a), at higher magnification a porous structure could be noticed (Figure $3 \mathrm{~b}$ ). After modification with $\mathrm{rGO}$, the presence of a film on the carbon SPE surface is noted, characteristic of the overlapping of rGO sheets (Figure 3c). The presence of white particles having a few micrometers in size is due to the contamination with salts (see $\mathrm{Na}$ peak in EDS analysis) from the buffer solution used in the electrochemical reduction of graphene oxide. With the deposition of gold and nickel hydroxide, the characteristic of the rGO film changes completely with the presence of several gold/ nickel hydroxide nanoparticles with size in the $50 \mathrm{~nm}$ range. The metallic nanoparticles on $\mathrm{Ni}(\mathrm{OH})_{2} / \mathrm{AuNp} / \mathrm{rGO} / \mathrm{SPE}$ surface are best seen at a higher magnification (Figure 3d). The EDS analysis confirmed the presence of $\mathrm{Ni}$ and $\mathrm{Au}$, although the amount of $\mathrm{Au}$ seems to be much higher than Ni since the Au has a much higher intensity peak than $\mathrm{Ni}$.

\subsection{Electrochemical behavior of the electrodes in the absence and presence of $E G$}

Figure $4 \mathrm{a}$ and $4 \mathrm{~b}$ present the cyclic voltammetry curves obtained with GCE and GCE/rGO, respectively, in $0.50 \mathrm{~mol} \mathrm{~L}^{-1} \mathrm{KOH}$ in the absence and presence of $0.6 \mathrm{mmol}$ $\mathrm{L}^{-1}$ ethylene glycol. These curves show no ethylene glycol electrochemical response using both GCE and GCE/rGO in the studied potential range. However, when submitted to the cyclic voltammetry technique in the absence and presence of the analyte (EG) in alkaline media, the $\mathrm{Ni}(\mathrm{OH})_{2} / \mathrm{AuNp} /$ $\mathrm{rGO} / \mathrm{GCE}$ presented a voltammogram with three anodic peaks and three cathodic peaks (Figure 4d). The first and second anodic peaks ( 1 and 2 ) observed at $-0.07 \mathrm{~V}$ and $0.21 \mathrm{~V}$, respectively, refer to the adsorption of $\mathrm{OH}^{-}$on the gold surface, the peaks 4 and 5 at 0.48 and $0.36 \mathrm{~V}$, respectively, are related to $\alpha-\mathrm{Ni}(\mathrm{OH})_{2} / \gamma-\mathrm{NiOOH}$ redox pair $^{67-71}$. The peak 3 is related to the EG oxidation and responds to EG concentration. In the cathodic region, the potential peaks (6) and (7) at $0.08 \mathrm{~V}$ and $-0.13 \mathrm{~V}$, respectively, refer to the reduction of gold oxide and $\mathrm{OH}^{-}$desorption, respectively. The peak for nickel hydroxide oxide formation (4) coincides with the formation of compound $\mathrm{Au}(\mathrm{OH})_{3}$ (Figure 4c $)^{67-69,71}$.

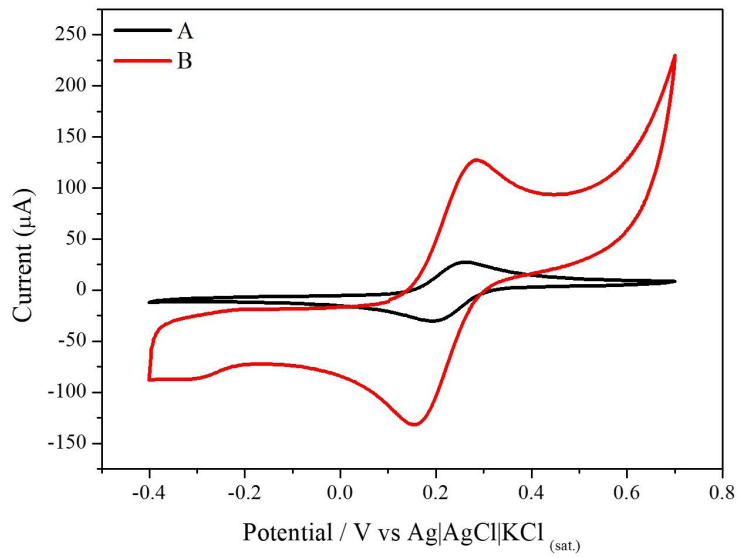

Figure 2. Voltammetric profile of the ferri-ferrocyanide couple at $20 \mathrm{mmol} \mathrm{L}^{-1}$ using (A) GCE and (B) reduced graphene oxide modified GCE, at $0.1 \mathrm{~V} \mathrm{~s}^{-1}$ scan rate.
Figure 4 shows that the synergism between nickel hydroxide and gold was especially important for the detection of EG. When only the $\mathrm{Ni}(\mathrm{OH})_{2} / \mathrm{rGO} / \mathrm{GCE}$ electrode was used (Figure 4c), it was not possible to observe any EG peak oxidation, while using the $\mathrm{AuNp} / \mathrm{rGO} / \mathrm{GCE}$ electrode (Figure 4d), an EG oxidation peak can be observed at approximately $0.3 \mathrm{~V}$ vs. $\mathrm{Ag} / \mathrm{AgCl}$. For the $\mathrm{Ni}(\mathrm{OH})_{2} / \mathrm{AuNp} /$ $\mathrm{rGO} / \mathrm{GCE}$ electrode (Figure $4 \mathrm{e}$ ) an $\mathrm{EG}$ oxidation peak is observed at $0.19 \mathrm{~V}$ vs. $\mathrm{Ag} / \mathrm{AgCl}$. The $\mathrm{Ni}(\mathrm{OH})_{2} / \mathrm{AuNp}$ composite dislocated to more negative potential the EG oxidation peak consequently increasing its current response. These results show the beneficial effect of the composite, resulting in a more sensitive material.

Figure 4 shows the benefit of the electrode modifications from an analytical point of view, in Table 1 it is possible to observe the electrochemically active area and $\mathrm{k}^{0}$ parameters of the electrodes.

Table 1 shows that the changes were considerably beneficial for the electrode. Comparing the unmodified electrode and the final electrode, there was an increase of 2.7 times in the electroactive area, and of 12.9 times in $\mathrm{k}^{0}$ and a decrease of the charge transfer resistance of 0.68 times. These results corroborate the analytical study of the electrodes, showing the importance of its modifications for quantification of the analyte, as these are parameters that will directly affect the analytical efficiency it. Analyzing the electrodes AuNp/rGO/ $\mathrm{GCE}$ and $\mathrm{Ni}(\mathrm{OH}) 2 / \mathrm{AuNp} / \mathrm{rGO} / \mathrm{GCE}$ it is possible to observe the importance of the synergism of metals, since there was an increase of 1.09 times of the area and 4.74 times of $\mathrm{k}^{0}$ and a decrease of 0.73 times in charge transfer resistance (Rct) (all curves are shown in Figure S3).

These results were already expected once that the composites based on the deposition of nickel hydroxide on gold show a great improvement in the catalytic efficiency of the electrode. The presence of gold allows a greater amount of physically and electrically adhered nickel hydroxide on the surface, decreases the film resistivity, decreases the nickel particle size, and allows a greater number of active sites because gold facilitates the oxidation of nickel oxide. It's important to highlight that the use of noble metals improves the adsorption of species on the electrode surface and their ability to remove species that may decrease the electrocatalytic efficiency of the electrode ${ }^{28,67,72}$.

The use of the alkaline medium is important for the alcohols electrooxidation because in this medium $\mathrm{M}-\mathrm{OH}_{\text {ads }}$ is formed (Reaction 1). The previous literature showed that with the increase of $\mathrm{OH}^{-}$concentration causes a higher $\mathrm{OH}^{-}$coverage on the metal surface, enhancing the kinetic of alcohol electrooxidation ${ }^{73}$.

The classic mechanisms for the oxidation of alcohols by transition metals in an alkaline medium involve hydroxyl radicals adsorbed on the electrode surface, which participate

Table 1. Study of the electrochemically active area and $\mathrm{k}^{0}$.

\begin{tabular}{cccc}
\hline Electrode & Area $\left(\mathrm{cm}^{2}\right)$ & $\mathrm{k}^{0}\left(\mathrm{~cm} \mathrm{~s}^{-1}\right)$ & Rct $\left(\Omega \mathrm{cm}^{2}\right)$ \\
\hline $\mathrm{GCE}$ & $4.75 \times 10^{-2}$ & $2.45 \times 10^{-3}$ & 570 \\
\hline $\mathrm{rGO} / \mathrm{GCE}$ & $7.32 \times 10^{-2}$ & $1.32 \times 10^{-2}$ & 466 \\
\hline $\mathrm{AuNp} / \mathrm{rGO} / \mathrm{GCE}$ & $1.17 \times 10^{-1}$ & $6.69 \times 10^{-3}$ & 527 \\
\hline $\begin{array}{c}\mathrm{Ni}(\mathrm{OH})_{2} / \mathrm{AuNp} / \mathrm{rGO} / \\
\mathrm{GCE}\end{array}$ & $1.28 \times 10^{-1}$ & $3.17 \times 10^{-2}$ & 385 \\
\hline
\end{tabular}



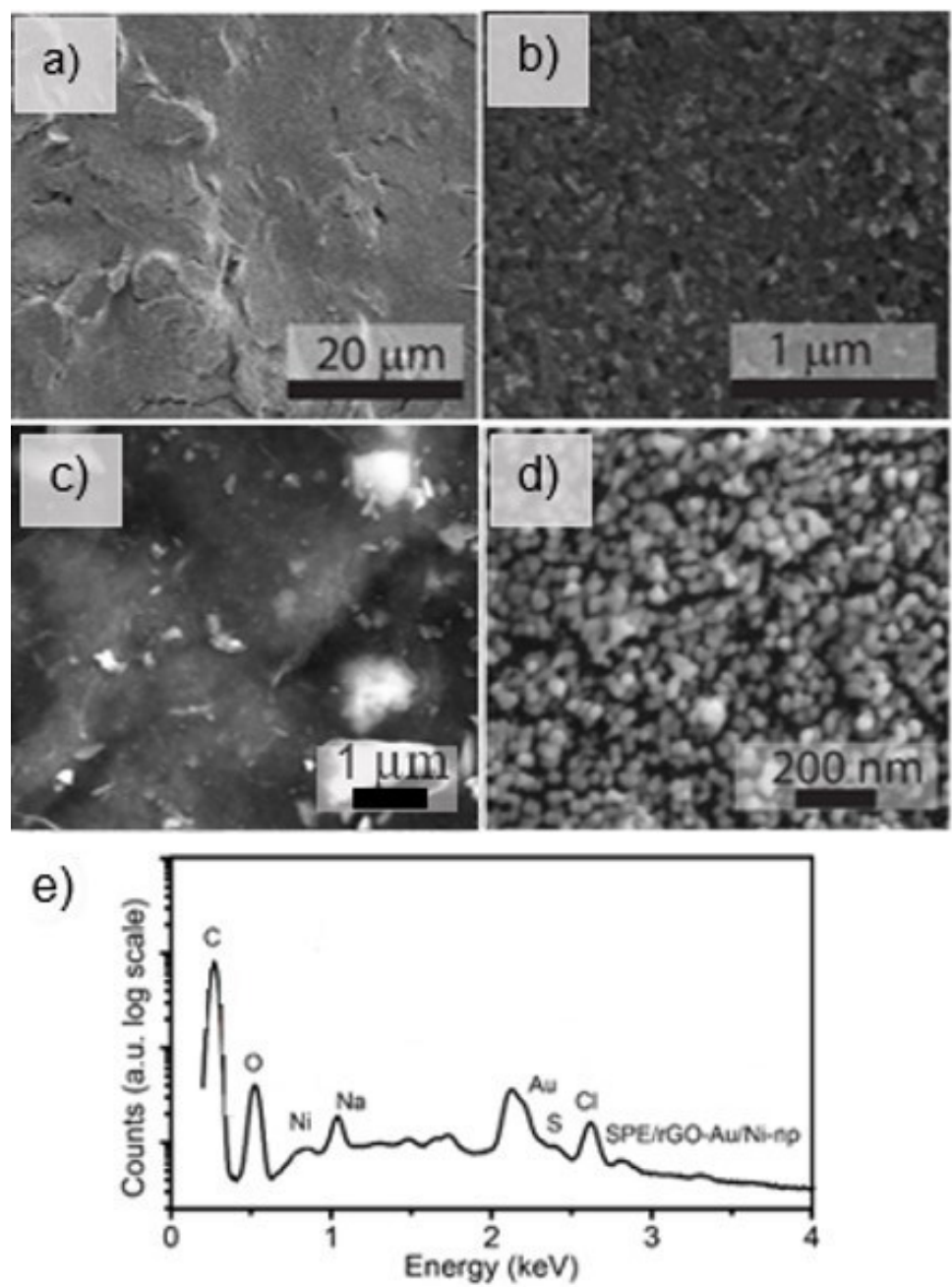

Figure 3. SEM analyses of the electrodes (a) and (b) carbon SPE (at two different magnifications), (c) rGO modified carbon SPE and (d) $\mathrm{Ni}(\mathrm{OH})_{2} / \mathrm{AuNp} / \mathrm{rGO}$ modified carbon SPE and (e) EDS chemical analyses of $\mathrm{Ni}(\mathrm{OH})_{2} / \mathrm{AuNp} / \mathrm{rGO} / \mathrm{SPE}$.

in the electron transfer step, favored in a basic medium, as can be seen below:

- $\quad \mathrm{M}+\mathrm{ROH} \rightarrow{\mathrm{M}-\mathrm{ROH}_{\mathrm{ads}}}$ (Reaction 1)

- $\quad \mathrm{M}-\mathrm{OH}-\rightarrow \mathrm{M}-\mathrm{OH}_{\mathrm{ads}}+\mathrm{e}-($ Reaction 2$)$

- $\quad \mathrm{M}-\mathrm{ROH}_{\mathrm{ads}}+\mathrm{M}-\mathrm{OH}_{\mathrm{ads}} \rightarrow$ products (Reaction 3)

- $\quad \mathrm{M}-\mathrm{ROH}_{\mathrm{ads}}+\mathrm{OH}-\rightarrow$ products + e- (Reaction 4)

The cyclic voltammetry technique was chosen as the electroanalytical technique to quantify EG to regenerate the active sites of electrode removing the poisoning intermediates.

\subsection{Partial validation}

\subsubsection{Linearity}

Figure 5 shows the relationship between the EG oxidation peak area and the EG concentration, in the range from 0.24 to $1.43 \mathrm{mmol} \mathrm{L}^{-1}$, in $0.50 \mathrm{~mol} \mathrm{~L}^{-1} \mathrm{KOH}$ solution. For the proposed analytical curve (Figure S4), was obtained a Pearson correlation coefficient of 0.9932 , greater than 0.9900 , and p-value of the F ANOVA test equal to $6.82^{x} 10^{-12}$, less than 0.05 , therefore showing that there is an adequate linear relationship between the parameters and significance of the applied linear model. To assess the homogeneity of variance and verify the confidence level of the analytical curve obtained, the Cochran test was applied at a significance level of $5 \%{ }^{50}$. The p-value obtained was 0.9304 , greater than 0.05 , so we do not reject the hypothesis of equality of variances at the $5 \%$ significance level, then it is a homoscedastic model. The evaluation of the standardized residuals vs. adjusted values shows that there is no value outside the range from -3 to 3 indicating that there are no outliers present and QQ-plot no value can affect the normality of the residuals (Figure S5).

\subsubsection{Limit of detection and quantification}

The LOD and LOQ represent the lower concentration of analyte that can be detect and quantified, respectively. According to Equation 5, the detection and quantification limits obtained were 49 and $162 \mu \mathrm{mol} \mathrm{L}^{-1}$, respectively.

\subsubsection{Precision and recovery}

The repeatability of the three different EG concentration levels (low, medium, and high) were verified in triplicate. The relative standard deviation for $0.24,0.72$ and $1.43 \mathrm{mmol} \mathrm{L}^{-1} \mathrm{EG}$ was calculated (Table S5). Relative 


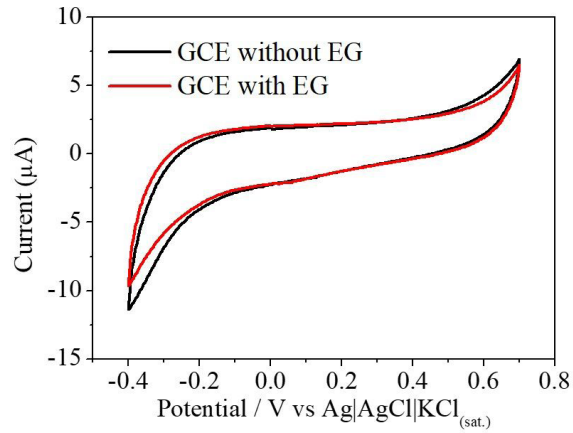

(a)

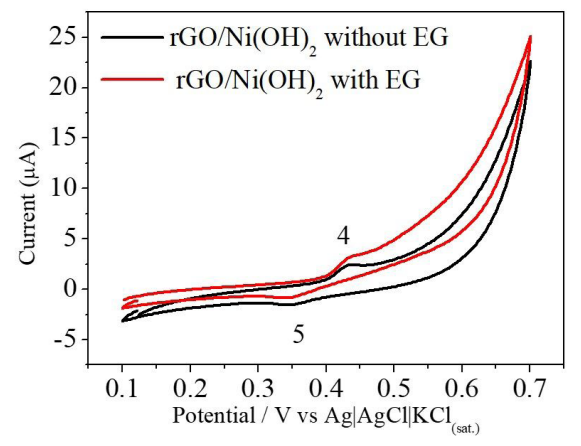

(c)

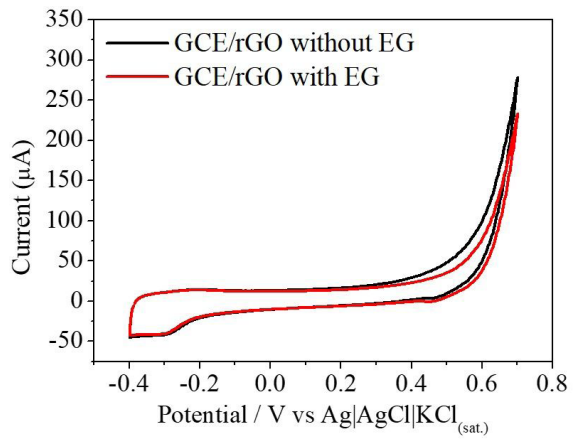

(b)

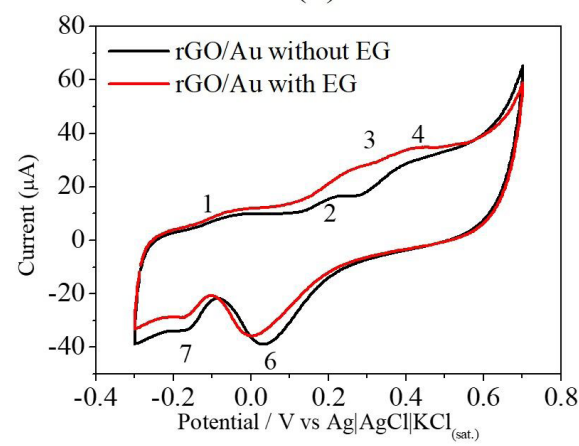

(d)

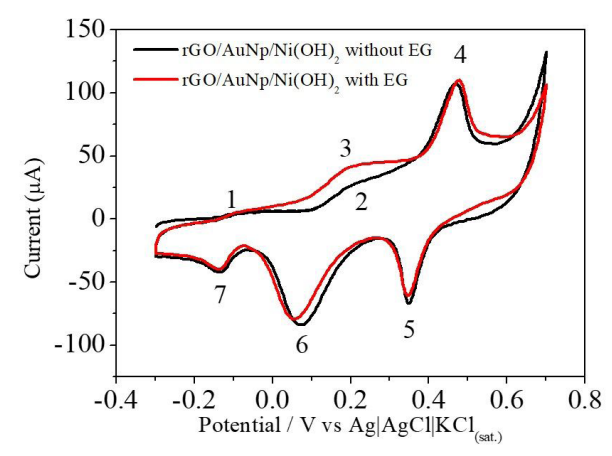

(e)

Figure 4. Cyclic voltammograms of GCE (a), GCE/rGO (b), $\mathrm{Ni}(\mathrm{OH})_{2} / \mathrm{rGO} / \mathrm{GCE}$ (c), AuNp/rGO/GCE (d) and Ni(OH) $/ 2 / \mathrm{AuNp} / \mathrm{rGO} / \mathrm{GCE}$ (e) in presence and absence of $0.6 \mathrm{mmol} \mathrm{L}^{-1}$ ethylene glycol in $0.50 \mathrm{~mol} \mathrm{~L}^{-1} \mathrm{KOH}$ at a scan rate of $50 \mathrm{mV} \mathrm{s}^{-1}$.

standard deviation values less than $5 \%$ are considered suitable for analytical methods ${ }^{58}$. According to the values obtained (Table S5), for all concentration levels, the relative standard deviation was below the analytically acceptable criterion, having been obtained $2.6,3.1$ and $1.5 \%$, respectively.

To study the recovery of the method, standard EG solutions with known concentrations (theoretical value) at $0.24,0.48,0.72,0.95,1.20$ and $1.43 \mathrm{mmol} \mathrm{L}^{-1}$ were used. The results presented in Table S6 show that the method has a good recovery (acceptance criteria 70-120\% ${ }^{74}$ in the concentration range studied, ranging from 97 to $109 \%$.

\subsubsection{Selectivity}

The selectivity of the method was performed by evaluating the electrochemical response of the electrode in the presence of ethanol, methanol, glycerol, and ethylene glycol at a concentration of $0.4 \mathrm{mmol} \mathrm{L}^{-1}$. As can be seen from Figure S6, in the studied concentration, no alcohol showed an oxidation peak at the same potential as EG. The glycerol oxidation peak appeared at approximately $0 \mathrm{Vvs} . \mathrm{Ag} / \mathrm{AgCl}$, this value potential is much more negative compared to the EG, while methanol and ethanol did not present an oxidation peak at this concentration.

\section{6. $\mathrm{Ni}(\mathrm{OH})_{2} / \mathrm{AuNp} / \mathrm{rGO} / G C E$ stability}

The electrode stability is one of the most important factors to evaluate its use in industry. An electrode with good stability will provide a less expensive and laborious analysis. When subjected to 500 cycles in the presence of $1.8 \mathrm{mmol} \mathrm{L}^{-1} \mathrm{EG}$, under conditions of $0.05 \mathrm{~V} \mathrm{~s}^{-1}$ and potential range -0.3 to $0.7 \mathrm{~V}$, the electrode did not lose signal after 500 cycles with RSD of $4.2 \%(<5 \%)$. The results showed that the dispersion between the readings is extremely low, which indicates high stability of the electrode for EG analysis (Figure S7). 
Table 2. Comparison of some analytical parameters for the proposed method with other methods found in the literature.

\begin{tabular}{|c|c|c|c|c|c|}
\hline Technique & Electrode & $\mathrm{LOD}\left(\mathrm{mmol} \mathrm{L}^{-1}\right)$ & LOQ $\left(\mathrm{mmol} \mathrm{L}^{-1}\right)$ & $\begin{array}{l}\text { Linear Range } \\
\left(\mathrm{mmol} \mathrm{L}{ }^{-1}\right)\end{array}$ & Reference \\
\hline CG (ASTM D4291-04) & - & - & - & 0.0805 to 3.22 & Drews $^{75}$ \\
\hline LC-MS/MS & - & 0.564 & 4.83 & 1.61 to 64.4 & Dziadosz $^{16}$ \\
\hline HS-CG & - & - & 0.161 & 0.161 to 32.2 & Ehlers et al. ${ }^{18}$ \\
\hline GC-MS & - & 0.806 & - & 0.806 to 80.6 & Hložek et al. ${ }^{17}$ \\
\hline Chronoamperometry & Copper & 0.0100 & - & 0.0100 to 1.50 & $\mathrm{Hu}$ and Wang ${ }^{5}$ \\
\hline Photoelectrochemical & $\mathrm{Ti} / \mathrm{TiO}_{2}$ nanotubes & 0.00720 & 0.0238 & 0.0300 to 880 & Ojani et al. ${ }^{76}$ \\
\hline Cyclic Voltammetry & $\mathrm{Ni} / \mathrm{Ni}(\mathrm{OH})_{2}$ & 0.651 & 2.15 & 2.20 to 13.2 & 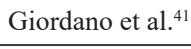 \\
\hline Cyclic Voltammetry & $\begin{array}{c}\mathrm{Ni}(\mathrm{OH})_{2} / \mathrm{AuNp} / \\
\mathrm{rGO} / \mathrm{GCE}\end{array}$ & 0.0490 & 0.162 & 0.240 to 1.43 & Our study \\
\hline
\end{tabular}

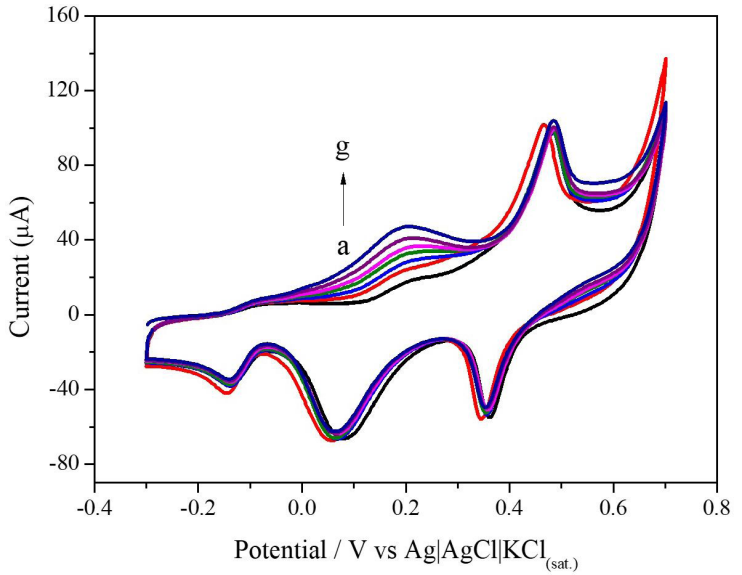

Figure 5. The cyclic voltammograms for different $\mathrm{EG}$ concentrations using $\mathrm{Ni}(\mathrm{OH})_{2} / \mathrm{AuNp} / \mathrm{rGO} / \mathrm{GCE}$ in $0.50 \mathrm{~mol} \mathrm{~L}^{-1} \mathrm{KOH}$ at $50 \mathrm{mV} \mathrm{s}^{-1}$ scan rate. The voltammograms are a, b, c, d, e, f and g are related to the EG concentrations at $0,0.24,0.48,0.72,0.95,1.20$ and $1.43 \mathrm{mmol} \mathrm{L}^{-1}$, respectively.

\subsection{Comparison with the literature data}

Table 2 compares some analytical parameters towards the EG analysis for the proposed method with other methods found in the literature. The chromatographic and mass methods present high detection or quantification limits besides, they are more expensive using large amounts of solvents and time-consuming for derivatization of the sample.

Although the method of this work presents a higher detection limit than the method using $\mathrm{Ti} / \mathrm{TiO}_{2}$ nanotubes electrode, the $\mathrm{Ni}(\mathrm{OH})_{2} / \mathrm{AuNp} / \mathrm{rGO} / \mathrm{GCE}$ sensor lacks any special apparatus for UV emission, making it a more practical analysis.

The standard method for trace ethylene glycol analysis in lubricating oil is the ASTM D4291-04 (2017) ${ }^{75}$, according to this normalized method the EG can be quantified in the range from 0.0805 to $3.22 \mathrm{mmol} \mathrm{L}^{-1}$ using the gas chromatograph technique. For human health concentrations above of $138 \mu \mathrm{m} / \mathrm{L}$ are capable to cause damage to the liver and kidney ${ }^{77}$. Therefore, the proposed method would be suitable for application in the detection and quantification of EG in several matrices.

\section{Conclusion}

The proposed electrode $\mathrm{Ni}(\mathrm{OH}) 2 / \mathrm{AuNp} / \mathrm{rGO} / \mathrm{GCE}$ showed that the electrode modification was extremely favorable, with a considerable increase in both electrically active area and heterogeneous electron transfer rate constant $\left(\mathrm{k}^{0}\right)$, with an increase of $176 \%$ in the electroactive area and $1194 \%$ in $\mathrm{k}^{0}$. It is worth mentioning the importance of the mixture of metals, synergism between nickel and gold nanoparticles provided a $374 \%$ increase in the $\mathrm{k}^{0}$.

The influence of these parameters can be observed in the analytical studies of the electrode where they were obtained a low limit of detection and quantification (49 and $162 \mu \mathrm{mol} \mathrm{L}^{-1}$, respectively), with good repeatability and, good stability, not losing efficiency after 500 cycles. The results obtained in this study show that the formed nanocomposite film has a good electrocatalytic activity for EG oxidation, thus being a good alternative for use as an electrode for alcohols analysis.

\section{Acknowledgments}

The authors thanks to Fundação de Amparo à Pesquisa do Estado do Rio de Janeiro (FAPERJ), Coordenação de Aperfeiçoamento de Pessoal de Nível Superior (CAPES) and Conselho Nacional de Desenvolvimento Científico e Tecnológico $(\mathrm{CNPq})$ for financial support. Victor Paiva would like to thank CNPq for the master's fellowship support.

\section{References}

1. Zaboon S, Soames A, Ghodkay V, Gubner R, Barifcani A. Recovery of mono-ethylene glycol by distillation and the impact of dissolved salts evaluated through simulation of field data. J Nat Gas Sci Eng. 2017;44:214-32.

2. Lee JB, Shon S, Kwon OS, Min JS, Kim NY, Paeng K-J. On-fiber derivatization for determination of ethylene glycol concentration in lubricant oil by SPME-GC/MS. Bull Korean Chem Soc. 2016;37(6):938-41.

3. Prodromidis MI, Veltsistas PG, Efstathiou CE, Karayannis MI. Amperometric detection of periodate using a graphite electrode modified with a novel $\alpha$-Keggin-type silicotungstic acid salt and determination of ethylene glycol in antifreeze fluids. Electroanalysis. 2001;13(11):960-6.

4. Gras K, Luong J, Lin M, Gras R, Shellie RA. Determination of ethylene glycol in lubricants by derivatization static headspace gas chromatography. Anal Methods. 2015;7(13):5545-50. 
5. Hu X, Wang J. A simple route of modifying copper electrodes for the determination of methanol and ethylene glycol. Electroanalysis. 2012;24(7):1639-45.

6. Lee JW, Lee J, Kang SP. 13C NMR spectroscopies and formation kinetics of gas hydrates in the presence of monoethylene glycol as an inhibitor. Chem Eng Sci. 2013;104:755-9.

7. Semenov AP, Medvedev VI, Gushchin PA, Yakushev VS, Vinokurov VA. Inhibiting gas hydrate formation by polymermonoethylene glycol mixture. Chem Technol Fuels Oils. 2016;52(1):43-51.

8. Luong J, Gras R, Cortes HJ, Shellie RA. Determination of trace ethylene glycol in industrial solvents and lubricants using phenyl boronic acid derivatization and multidimensional gas chromatography. Anal Chim Acta. 2013;805:101-6.

9. Paeng K-J, Kwon O-S, Sung T-M, et al. The comparison of derivatization methods for the determination of ethylene glycol in lubricant oil sample by GC/MS. Bull Korean Chem Soc. 2013;33:4243-6.

10. Tomala A, Karpinska A, Werner WSM, Olver A, Störi H. Tribological properties of additives for water-based lubricants. Wear. 2010;269(11-12):804-10.

11. Xu S, Fan S, Wang Y, Lang X. Recovery of monoethylene glycol combined with kinetic hydrate inhibitor. Chem Eng Sci. 2017;171:293-302.

12. Braga AP. Recuperação de monoetilenoglicol em coluna de destilação de película descendente [dissertation]. Rio de Janeiro: Federal University of Rio de Janeiro; 2016.

13. Nagesh IV, Koley KC, Sen S, Mohan S, Sahu S. Ethylene glycol poisoning. Med J Armed Forces India. 2015;71:S36-8.

14. Hodgman MJ, Krenzelok E, Wezorek C. Toxic inhalation of ethylene glycol: a pharmacological improbability. Clin Toxicol. 1997;35:109-11.

15. Dianyi Yu M. Ethylene glycol and propylene glycol toxicity. Atlanta: Agency for Toxic Substances and Disease Registry; 2010. 65 p. (Case Studies in Environmental Medicine).

16. Dziadosz M. Direct analysis of ethylene glycol in human serum on the basis of analyte adduct formation and liquid chromatography-tandem mass spectrometry. J Chromatogr B Analyt Technol Biomed Life Sci. 2018;1072:100-4.

17. Hložek T, Bursová M, Čabala R. Simultaneous and cost-effective determination of ethylene glycol and glycolic acid in human serum and urine for emergency toxicology by GC-MS. Clin Biochem. 2015;48(3):189-91.

18. Ehlers A, Morris C, Krasowski MD. A rapid analysis of plasma/serum ethylene and propylene glycol by headspace gas chromatography. Springerplus. 2013;2(1):203.

19. Saumya V, Prathish KP, Rao TP. In situ copper oxide modified molecularly imprinted polypyrrole film based voltammetric sensor for selective recognition of tyrosine. Talanta. 2011;85(2):105662.

20. Luo J, Cong J, Fang R, Fei X, Liu X. One-pot synthesis of a graphene oxide coated with an imprinted sol-gel for use in electrochemical sensing of paracetamol. Mikrochim Acta. 2014;181(11-12):1257-66.

21. Anastas PT, Kirchhoff MM. Origins, current status, and future challenges of green chemistry. Acc Chem Res. 2002;35(9):68694.

22. Yáñez-Sedeño P, Campuzano S, Pingarrón JM. Electrochemical (bio)sensors: promising tools for green analytical chemistry. Curr Opin Green Sustainable Chem. 2019;19:1-7.

23. Guo H, Huang Z, Zheng Y, et al. Electrodeposition of nickel nanoparticles modified glassy carbon electrode for nonenzymatic glucose biosensing. Int J Electrochem Sci. 2015;10:10703-12.

24. Neiva EGC, Oliveira MM, Bergamini MF, Marcolino LH $\mathrm{Jr}$, Zarbin AJG. One material, multiple functions: graphene/ $\mathrm{Ni}(\mathrm{OH}) 2$ thin films applied in batteries, electrochromism and sensors. Sci Rep. 2016;6(1):33806.
25. Natarajan C, Matsumoto H, Nogami G. Improvement in electrochromic stability of electrodeposited nickel hydroxide thin film. J Electrochem Soc. 1997;144(1):121-6.

26. Yao K, Zhai M, Ni Y. $\alpha-\mathrm{Ni}(\mathrm{OH}) 2 \cdot 0.75 \mathrm{H} 2 \mathrm{O}$ nanofilms on $\mathrm{Ni}$ foam from simple $\mathrm{NiCl} 2$ solution: fast electrodeposition, formation mechanism and application as an efficient bifunctional electrocatalyst for overall water splitting in alkaline solution. Electrochim Acta. 2019;301:87-96.

27. Zaleska-Medynska A, Marchelek M, Diak M, Grabowska E. Noble metal-based bimetallic nanoparticles: the effect of the structure on the optical, catalytic and photocatalytic properties. Adv Colloid Interface Sci. 2016;229:80-107.

28. Rinaldi AL, Rodríguez-Castellón E, Sobral S, Carballo R. Application of a nickel hydroxide gold nanoparticles screenprinted electrode for impedimetric sensing of glucose in artificial saliva. J Electroanal Chem. 2019;832:209-16.

29. Yuan B, Xu C, Deng D, Xing Y, Liu L, Pang H, et al. Graphene oxide/nickel oxide modified glassy carbon electrode for supercapacitor and nonenzymatic glucose sensor. Electrochim Acta. 2013;88:708-12.

30. Shen Y, Dastafkan K, Sun Q, Wang L, Ma Y, Wang Z, et al. Improved electrochemical performance of nickel-cobalt hydroxides by electrodeposition of interlayered reduced graphene oxide. Int J Hydrogen Energy. 2019;44(7):3658-67.

31. Mierczynski P, Vasilev K, Mierczynska A, Maniukiewicz W, Szynkowska MI, Maniecki TP. Bimetallic $\mathrm{Au}-\mathrm{Cu}, \mathrm{Au}-\mathrm{Ni}$ catalysts supported on MWCNTs for oxy-steam reforming of methanol. Appl Catal B. 2016;185:281-94.

32. Han GF, Xiao BB, Lang XY, Wen Z, Zhu Y-F, Zhao M, et al Self-grown $\mathrm{Ni}(\mathrm{OH}) 2$ layer on bimodal nanoporous AuNi alloys for enhanced electrocatalytic activity and stability. ACS Appl Mater Interfaces. 2014;6(19):16966-73.

33. Maduraiveeran G, Rasik R, Sasidharan M, Jin W. Bimetallic gold-nickel nanoparticles as a sensitive amperometric sensing platform for acetaminophen in human serum. J Electroanal Chem. 2018;808:259-65.

34. Rocha DP, Dornellas RM, Cardoso RM, Narciso LCD, Silva MNT, Nossol E, et al. Chemically versus electrochemically reduced graphene oxide: improved amperometric and voltammetric sensors of phenolic compounds on higher roughness surfaces. Sens Actuators B Chem. 2018;254:701-8.

35. Yang J, Gunasekaran S. Electrochemically reduced graphene oxide sheets for use in high performance supercapacitors. Carbon N Y. 2013;51:36-44.

36. Rocha DP, Dornellas RM, Nossol E, Richter EM, Silva SG, Santana MHP, et al. Electrochemically reduced graphene oxide for forensic electrochemistry: detection of cocaine and its adulterants paracetamol, caffeine and levamisole. Electroanalysis. 2017;29(11):2418-22.

37. Yang L, Liu D, Huang J, You T. Simultaneous determination of dopamine, ascorbic acid and uric acid at electrochemically reduced graphene oxide modified electrode. Sens Actuators B Chem. 2014;193:166-72.

38. Hummers WS Jr, Offeman RE. Preparation of Graphitic Oxide. J Am Chem Soc. 1958;80(6):1339.

39. Castro KLS, Oliveira SM, Curti RV, et al. Electrochemical response of glassy carbon electrodes modified using graphene sheets of different sizes. Int J Electrochem Sci. 2018;13:71-87.

40. Shen Y, Dastafkan K, Sun Q, Wang L, Ma Y, Wang Z, et al. Improved electrochemical performance of nickel-cobalt hydroxides by electrodeposition of interlayered reduced graphene oxide. Int J Hydrogen Energy. 2019;44(7):3658-67.

41. Giordano GF, Camargo CL, Vieira LCS, d'Ávila MA, Couto BC, Carvalho RM, et al. Turbulence-assisted high-throughput liquidliquid extraction in microfluidics and $\mathrm{Ni}(\mathrm{OH})_{2}$ nanoparticles for electrochemical determination of monoethylene glycol traces in natural gas condensate. Energy Fuels. 2018;32(6):6577-83. http://dx.doi.org/10.1021/acs.energyfuels.8b00725. 
42. Bhatti NK, Subhani MS, Khan AY, et al. Heterogeneous electron transfer rate constants of viologen at a platinum disk electrode. Turk J Chem. 2005;29:659-68.

43. Nicholson RS. Theory and application of cyclic voltammetry for measurement of electrode reaction kinetics. Anal Chem. 1965;37(11):1351-5.

44. Randviir EP. A cross examination of electron transfer rate constants for carbon screen-printed electrodes using Electrochemical Impedance Spectroscopy and cyclic voltammetry. Electrochim Acta. 2018;286:179-86.

45. Neghmouche N, Khelef A, Lanez T. Electrochemistry characterization of ferrocene/ferricenium redox couple at glassycarbon electrode. J Fundam Appl Sci. 2015;1(2):23.

46. Neghmouche NS, Lanez T. Calculation of electrochemical parameters starting from the polarization curves of ferrocene at glassy carbon electrode. Phys Astron. 2013;9:37-45.

47. Ngamchuea K, Eloul S, Tschulik K, Compton RG. Planar diffusion to macro disc electrodes: what electrode size is required for the Cottrell and Randles-Sevcik equations to apply quantitatively? J Solid State Electrochem. 2014;18(12):3251-7.

48. Zhu P, Zhao Y. Cyclic voltammetry measurements of electroactive surface area of porous nickel: peak current and peak charge methods and diffusion layer effect. Mater Chem Phys. 2019;233:60-7.

49. U.S. Departament of Health and Human Services. Q2B validation of analytical procedures: methodology [Internet]. FDA; 1996 [cited 2020 Jan 10]. Available from: http://www.fda.gov/cder/ guidance/index.htmorhttp://www.fda.gov/cber/guidelines.htm

50. Rego ECP. Internal publication of method validation course. Rio de Janeiro: INMETRO; 2013.

51. Cochran WG. The distribuition of the largest of a set of estimated variances as a fraction of their total. Ann Eugen. 1941;11(1):4752.

52. Anderson TW, Darling DA. Asymptotic theory of certain 'Goodness of Fit' criteria based on stochastic processes. Ann Math Stat. 1952;23(2):193-212.

53. Ross SM. Introductory statistics. 3rd ed. New Delhi: Elsevier; 2010. http://dx.doi.org/10.1016/B978-0-12-374388-6.50002-7.

54. Honório GG, Cunha JN, Santos Castro Assis KL, Aguiar PF, Andrade DF, Souza CG, et al. Free glycerol determination in biodiesel samples using palladium nanoparticles modified glassy carbon electrode associated with solid phase extraction. J Solid State Electrochem. 2019;23(11):3057-66.

55. Mesquita Brito N, Possidônio Amarante ODE Jr, Polese L, et al. Validação de métodos analíticos: estratégia e discussão. Pestic Rev Ecotoxicologia e Meio Ambient. 2003;13:129-46.

56. Bassani de Barros C. Validação de métodos analíticos. Biologico. 2002;64:175-7.

57. Muniz RDO, Martins SB, Honório GG, Cunha JN, Souza CG, Andrade DF, et al. Total glycerol analysis in biodiesel samples using solid phase extraction coupled with enzymatic-spectrophotometric determination. Anal Methods. 2019;11(6):767-73.

58. INMETRO: Instituto Nacional de Metrologia, Qualidade e Tecnologia. Guidance on validating chemical testing methods. Brasília: INMETRO; 2007.

59. Jorio A, Saito R, Dresselhaus G, Dresselhaus MS. Raman spectroscopy in graphene related systems. Weinheim: Wiley-VCH Verlag GmbH \& Co. KGaA; 2011. http://dx.doi. org/10.1002/9783527632695.

60. Kaniyoor A, Ramaprabhu S. A Raman spectroscopic investigation of graphite oxide derived graphene. AIP Adv. 2012;2(3):032183. http://dx.doi.org/10.1063/1.4756995.

61. Marcano DC, Kosynkin DV, Berlin JM, Sinitskii A, Sun Z, Slesarev A, et al. Improved synthesis of graphene oxide. ACS Nano. 2010;4(8):4806-14

62. Yuan G, Li X, Dong Z, Westwood A, Cui Z, Cong Y, et al. Graphite blocks with preferred orientation and high thermal conductivity. Carbon. 2012;50(1):175-82.
63. Castro KLS, Curti RV, Araujo JR, Landi SM, Ferreira EHM, Neves RS, et al. Calcium incorporation in graphene oxide particles: A morphological, chemical, electrical, and thermal study. Thin Solid Films. 2016;610:10-8.

64. Li D, Kaner RB. Materials science: graphene-based materials. Mater Sci. 2008;320:1170-1.

65. Pumera M, Ambrosi A, Bonanni A, Chng ELK, Poh HL. Graphene for electrochemical sensing and biosensing. Trends Analyt Chem. 2010;29(9):954-65.

66. Castro KLS, Oliveira SM, Curti RV, et al. Electrochemical response of glassy carbon electrodes modified using graphene sheets of different sizes. Int J Electrochem Sci. 2018;13:71-87.

67. Burke LD, Nugent PF. The electrochemistry of gold: I. The redox behaviour of the metal in aqueous media. Gold Bull. 1997;30(2):43-53.

68. Burke LD, Lyons MEG. Modern aspects of electrochemistry. 1st ed. New York: Academic Press; 1986.

69. Peñafiel RMD. Comportamento eletroquímico do ouro na presença de alcoóis alquílicos e amilxantato de potássio [dissertation]. Rio de Janeiro: COPPE, Federal University of Rio de Janeiro ; 2007.

70. Oliveira R, Pissetti FL, Lucho AMS. FTO modified eletrodes by direct gold electrodeposition: production, characterization and electrochemical sensor aplication. Quim Nova. 2016;39:146-55.

71. Santos CS. Desenvolvimento de diferentes dispositivos eletroqímicos a base de ouro aplicados como sensores e biossensores [thesis]. Ponta Grossa: State University of Ponta Grossa; 2016.

72. Xu J, Chen T, Qiao X, Sheng Q, Yue T, Zheng J. The hybrid of gold nanoparticles and $\mathrm{Ni}(\mathrm{OH}) 2$ nanosheet for non-enzymatic glucose sensing in food. Colloids Surf A Physicochem Eng Asp. 2019;561:25-31.

73. Mahapatra SS, Datta J. Characterization of Pt-Pd/C electrocatalyst for methanol oxidation in alkaline medium. Int J Electrochem. 2011;2011:1-16.

74. Mesquita P L, Afonso RJCF, Aquino SF, Leite GS. Validação de método de cromatografia líquida para a determinação de sete ácidos graxos voláteis intermediários da digestão anaeróbia. Eng Sanit Ambient. 2013;18(4):295-302.

75. Drews A. Standard test method for trace ethylene glycol in used engine oil. In: ASTM International. Manual on hydrocarbon analysis. 6th ed. West Conshohocken: ASTM International; 2008. p. 670-2.

76. Ojani R, Khanmohammadi A, Raoof JB. Ti/ $/ \mathrm{TiO}_{2}$ nanotube array electrode as a new sensor to photoelectrocatalytic determination of ethylene glycol. Bull Mater Sci. 2016;39(1):13-7.

77. CDC: Centers for Disease Control and Prevention. National Institute for Occupational Safety and Health (NIOSH). Registry of Toxic Effects of Chemical Substances (RTECS): KW2975000: Ethylene glycol [Internet]. Atlanta: CDC/NIOSH; 2020 [cited 2020 June 26]. Available from: https://www.cdc.gov/niosh-rtecs/ KW2D6518.html

\section{Supplementary material}

The following online material is available for this article: Figure S1 - Surface response plots for the EG determination obtained via CCD.

Figure S2 - Voltammetric profile of $20 \mathrm{mmol} \mathrm{L}^{-1}$ ferriferrocyanide couple in $3 \mathrm{~mol} \mathrm{~L}^{-1} \mathrm{KCl}$ using $\mathrm{GCE}, \mathrm{rGO} /$ $\mathrm{GCE}, \mathrm{Au} / \mathrm{rGO} / \mathrm{GCE}$ and $\mathrm{Ni}(\mathrm{OH})_{2} / \mathrm{Au} / \mathrm{rGO} / \mathrm{GCE}$ electrode at $0.1 \mathrm{~V} \mathrm{~s}^{-1}$ scan rate.

Figure S3 - The (a,b) Bode and (c) Nyquist plots of GCE, $\mathrm{rGO} / \mathrm{GCE}, \mathrm{Au} / \mathrm{rGO} / \mathrm{GCE}$ and $\mathrm{Ni}(\mathrm{OH})_{2} / \mathrm{Au} / \mathrm{rGO} / \mathrm{GCE}$ electrodes in $3 \mathrm{~mol} \mathrm{~L}^{-1} \mathrm{KCl}$ containing $20 \mathrm{mmol} \mathrm{L}^{-1}\left[\mathrm{Fe}(\mathrm{CN})_{6}\right]^{3-}$.

Figure S4 - The analytical curve for EG standards in $0.50 \mathrm{~mol} \mathrm{~L}^{-1} \mathrm{KOH}$ (EG oxidation peak area versus EG concentration) using $\mathrm{Ni}(\mathrm{OH})_{2} / \mathrm{AuNp} / \mathrm{rGO} / \mathrm{GCE}$ electrode. 
Figure S5 - Analysis of residuals of linear model.

Figure S6 - Electrode selectivity study in the presence of $0.4 \mathrm{mmol} \mathrm{L}^{-1}$ of ethanol, methanol, glycerol and ethylene glycol.

Figure $\mathrm{S} 7$ - Stability of $\mathrm{Ni}(\mathrm{OH})_{2} / \mathrm{AuNp} / \mathrm{rGO} / \mathrm{GCE}$ in $0.50 \mathrm{~mol} \mathrm{~L}^{-1} \mathrm{KOH}$ with $1.8 \mathrm{mmol} \mathrm{L}^{-1}$ of EG.

Table S1 - Experimental PB design matrix for the electrodeposition of gold and nickel nanoparticles.

Table S2 - Tests and response for $\mathrm{PB}$ design of $\mathrm{Ni}(\mathrm{OH})_{2} /$ $\mathrm{AuNp} / \mathrm{rGO} / \mathrm{GCE}$.
Table S3 - Effects of the studied parameters for the electrodeposition of nickel nanoparticles and gold nanoparticles.

Table S4 - Factors, levels, coded matrix and responses for $\mathrm{CCD}$ with triplicate in the central point for the electrodeposition of nickel and gold nanoparticles.

Table S5 - Relative standard deviation of the $\mathrm{Ni}(\mathrm{OH})_{2} /$ $\mathrm{AuNp} / \mathrm{rGO} / \mathrm{GCE}$.

Table S6 - Evaluation of the analytical recovery of the $\mathrm{Ni}(\mathrm{OH})_{2} / \mathrm{AuNp} / \mathrm{rGO} / \mathrm{GCE}$. 